\title{
Delayed-Release Phosphatidylcholine Is Effective for Treatment of Ulcerative Colitis: A Meta-Analysis
}

\author{
Wolfgang Stremmel $^{\mathrm{a}}$ Hüseyin Vural ${ }^{\mathrm{b}}$ Osman Evliyaoglu ${ }^{\mathrm{b}}$ Ralf Weiskirchen ${ }^{\mathrm{b}}$ \\ ${ }^{a}$ Medical Center Baden-Baden, Baden-Baden, Germany; ${ }^{b}$ Institute of Molecular Pathobiochemistry, Experimental \\ Gene Therapy and Clinical Chemistry, RWTH University Hospital Aachen, Aachen, Germany
}

\section{Keywords}

Ulcerative colitis · Phosphatidylcholine - Meta-analysis .

Microbiota $\cdot$ Clinical trial

\begin{abstract}
Background: Phosphatidylcholine (PC) is intrinsically missing in intestinal mucus of patients with ulcerative colitis. Topical supplementation with delayed intestinal release PC formulations is assumed to compensate this lack. Three monocenter randomized controlled trials (RCTs) with a $30 \%$ PC-containing lecithin were successful, whereas 1 trial with $>94 \%$ PC-containing lecithin failed. Objectives: Evaluation of $30 \%$ PC-containing lecithin provided in a delayed intestinal release formulation for treatment efficacy of ulcerative colitis was evaluated by meta-analysis of 3 RCTs. Methods: Meta-analysis of 3 studies was performed using RevMan 5.3 software. Odds ratio (OR) and $95 \% \mathrm{Cl}$ were calculated for remission, clinical and endoscopic improvement, histology, and life quality. $p$ values $<0.05$ were accepted as significant. Results: The meta-analysis of 3 RTCs with 160 included patients with ulcerative colitis verified that PC improved the rate of remission $(O R=9.68)$, as well as clinical $(O R=30.58)$ and endoscopic outcomes $(\mathrm{OR}=36.73)$. Within the available
\end{abstract} better. All effects were significant over placebo. Achieved remission was maintained in a higher percentage of patients under intestinal-release PC formulation than placebo. The profile of adverse events was identical to the placebo population. Conclusions: A 30\% PC-containing lecithin in delayed intestinal release formulation improves clinical and endoscopic outcomes, histologic activity, and quality of life in patients with ulcerative colitis. For the patients, lack of adverse events is an important consideration.

(c) 2021 S. Karger AG, Basel

\section{Introduction}

Intestinal mucus is protective against colonic microbiota invasion and consequent inflammation [1]. Responsible for this protection is the content of phosphatidylcholine (PC) [2]. It serves as a hydrophobic barrier to repel bacteria in the aqueous lumen from the mucosal surface [3]. Colonic mucus PC originates from secretion of systemic PC into the ileum. It originates from PC-containing split products of lipoproteins and passes through endothelial gaps into the interstitial space of intestinal 
mucosa $[4,5]$. Due to its complex chemical nature, PC cannot enter cells but accumulates with its positive charged head group at the negatively charged constitutional proteins of tight junctions between the apical sides of mucosal cells [4-7]. With time, excessive PC flip-flops to the luminal side and binds to enterocyte bound mucin 3. Translocation is driven by a negatively environment generated through apical bicarbonate and chloride secretion by cystic fibrosis transmembrane conductance regulator. From stationary mucin 3, PC is taken over by secretory mucin 2 originating from goblet cells embedded in the mucosal cell layer. The PC bound to mucin 2 appears as a fatty network, prohibiting luminal bacteria to enter the mucus. Between the hydrophobic bundles, an electrolyte-rich solution allows nutrients to enter the mucosa. The gross motility supported by microvilli mobility directs the mucus from small intestine through large intestine until release from rectum. During this passage, the mucus PC is broken down by bacterial ecto-phospholipases of the microbiota, which renders the rectum as location with lowest PC content and, thus, most vulnerable for bacterial invasion [7-10].

In ulcerative colitis, transport of PC across the tight junction or barrier is intrinsically distributed causing a lack of mucus PC down to $30 \%$ of normal values $[5,8,9]$. This may be sufficient under no-stress conditions. However, yet undefined circumstances may further reduce this level, for example, a higher bacterial ecto-phospholipase activity of the microbiota or reduced PC secretion due to ischemia, for example, by non-steroidal anti-inflammatory drug exposure [7]. Then bacterial invasion can occur and precipitate mucosal inflammation. The colitis always starts in rectum and reaches proximal parts of the colon (e.g., proctosigmoiditis, left-sided colitis, or pancolitis) according to the degree of PC depletion.

As symptomatic therapy, the topical application of PC to the colonic mucus via luminal provision was considered. It was assumed that luminally provided PC fills up the empty PC-binding sites on secretory mucin 2 and, thus, reestablishes a hydrophobic barrier. Indeed, in studies with a genetic mouse model of ulcerative colitis, the lack of PC in mucus was shown to be compensated by deep intestinal tube feeding with excessive PC [5]. In addition, this PC saturates the ecto-phospholipases of the microbiota which prevents the damaging consumption of the more difficult accessible mucus PC [10]. Finally, PC was reported to exert antiinflammatory activity [11].

Now it had to be proven that application of PC to the colonic lumen is helpful to improve human active ulcerative colitis. Orally provided conventional PC prepara- tions are completely absorbed and, thus, not available for the colonic mucus. Therefore, $\mathrm{PC}$ had to be encapsulated with a coating allowing delayed release in intestine. The applied PC formulations were evaluated in a number of clinical trials. Two different delayed release PC preparations were tested. First,a 30\% PC-containing lecithin encapsulated with Eudragit S-100 allowing intestinal release above $\mathrm{pH} 7.0$ [12-15], and second, a >94\% PC-containing lecithin with a gastric acid-resistant Eudragit L30-D-55 coating [16-18], which disintegrates at $\mathrm{pH} 5.5$ in the duodenum.

With the first formulation, 3 randomized controlled trials (RCTs) [12-14] were performed and 1 maintenance of remission observational trial [15]. With the second formulation, a phase IIB trial showed that a dose of $3.2 \mathrm{~g} \mathrm{PC}$ daily improves the simple colitis activity score [16]. A phase III multicenter RCT with this gastric acid resistant PC failed $[17,18]$. The first formulation was effective; however, the number of patients in each of the trials was low. Therefore, we performed here a meta-analysis of those 3 trials with a total of 160 patients to examine the treatment efficacy in patients with active ulcerative colitis employing the $30 \%$ PC-containing lecithin released in distal small intestine. Evaluation criteria were clinical remission and improvement of clinical and endoscopic course, histology and quality of live. The reported scores are those described in the trials which are based on the parameters obtained. We added on top the data of the observational maintenance of remission trial [15] and the collective adverse events profile observed in the RCTs [12-14].

\section{Methods}

For the meta-analysis, 3 RCTs of 1 center were combined with a total of 160 patients who were recruited over a total period of 10 years. The team of investigators varied over the years, but trials were performed by an internal standardized operational procedure. Patients were assessed by clinical and endoscopic evaluation, obtained histology, and a quality-of-life score. They were at least 18 years old, presented with long-term ulcerative colitis ( $>2$ years) with chronic active course ( $\geq 4$ months) and a clinical activity index (CAI) of $\geq 4$ [19]. Steroids and immunosuppressives were only allowed in the steroid refractory trial with an intention to taper them. Standard therapy with amino-salicylates or E. coli Nissle was allowed to be continued, but at constant doses for at least 4 weeks before entry in the trials. All therapies had to be stable for at least 4 weeks before entering the trials. Patients were treated with delayed intestinal release PC or undistinguishable placebo for 3 months. The study medication contained a 30\% PC enriched lecithin preparation encapsulated always with the same amount of Eudragit S-100 [12-15]. Different doses of PC were mixed with 
Table 1. Baseline characteristics of the total 160 patients included

\begin{tabular}{lcc}
\hline Treatment group & $\begin{array}{l}\text { PC group } \\
(n=90)\end{array}$ & $\begin{array}{l}\text { Placebo group } \\
(n=70)\end{array}$ \\
\hline Men/women, $n / n$ & $53 / 37$ & $40 / 30$ \\
Median age (IQR), yr & $37(24-58)$ & $37(25-52)$ \\
Median CAI score (IQR) & $9.0(6.1-12.3)$ & $8.4(6.0-11.7)$ \\
Median EAI score (IQR) & $7.2(6.3-8.0)$ & $6.8(6.1-7.8)$ \\
Median histologic index score (IQR) & $3.0(2.2-3.6)$ & $3.1(2.0-3.5)$ \\
Median IBDQ score (IQR) & $116(88-127)$ & $121(93-141)$ \\
\hline
\end{tabular}

PC, phosphatidylcholine; CAI, clinical activity index; EAI, endoscopic activity index; IQR, interquartile range; yr, years.

defined amounts of inert cellulose. Daily doses of $0 \mathrm{~g}(n=60), 0.5$ $\mathrm{g}(n=10), 1 \mathrm{~g}(n=10), 2 \mathrm{~g}(n=60), 3 \mathrm{~g}(n=10)$, or $4 \mathrm{~g}(n=10)$ PC were provided in the trials [12-15]. Outcome parameters were CAI [19] with a definition of clinical remission as CAI $\leq 3$ [20, 21], endoscopic activity index (EAI) [22], histology index [23], and life quality score using the inflammatory bowel disease questionnaire - German version (IBD Q-D) [24, 25].

In detail, the CAI ranges from 0 to 31 ; it comprises the sum of the following subscores: stool frequency $(0-3)$, blood in stool (0$4)$, general well-being ( $0-3)$, abdominal pain (0-3), anemia (0-4), elevated erythrocyte sedimentation rate (0-2), fever (0-3), and extraintestinal manifestations ( $0-9$ score points). The EAI ranges from $0-12$ index points. It contains the subscores of mucosal granulation $(0-2)$, reduced vascular pattern $(0-2)$, mucosal friability $(0-4)$, and mucosal coating/ulcerations ( $0-4$ score points). Histological appearance in a given biopsy was scored from 0 to 4 as follows: $0=$ no; 1 = mild inactive; $2=$ mild active; $3=$ moderate active; and $4=$ severe active inflammation. The score taken into account for evaluation was the median value of the rectal/sigmoidal mucosal biopsies. Response was defined as $\geq 50 \%$ improvement of the CAI, EAI, and IBD Q-D scores, and $\geq 25 \%$ improvement of the histology score.

The occurrence of adverse and serious adverse events was registered in all trials through both open interviews and written questionnaires [12-14]. For statistical analysis of the meta-analysis, we used the RevMan 5.3 software (Copenhagen: The Nordic Cochrane Centre, The Cochrane Collaboration, 2014). Odds ratio (OR) and 95\% CI were calculated for remission, clinical, endoscopic, histologic, and life quality improvement. The difference was statistically significant when $p<0.05$.

\section{Results}

The analyzed patient populations were at baseline comparable in regard to sex, age, disease activity, and life quality (Table 1). The outcome of the analyzed clinical trials is shown in Figure 1 and Table 2, where the figure shows the effect on disease activity parameters and the table the number of patients responding.
The 3 RCTs revealed an increased number of patients reaching clinical remission with $\mathrm{PC}$ in comparison to the placebo group (OR $=9.68,95 \%$ CI: $3.81-24.61, I^{2}=0 \%$, $z=4.77, p<0.00001$; Fig. 1a) [12-14]. In the dose finding trial [14], the group of $0.5 \mathrm{~g}$ PC was a priori assumed to have no therapeutic effect and should therefore serve as control. All other dose arms (1.0-4.0 g PC) were in fact significantly superior to the $0.5 \mathrm{~g}$ group. Thus, this subtherapeutic dose arm was added to the placebo groups of the other trials of this meta-analysis. The remaining dose groups, including the $1 \mathrm{~g}$ PC population, were all taken as PC-treated patients.

Furthermore, clinical activity, endoscopic appearance, histology, and life quality improved in the PC groups (Fig. 1b-e). As shown in Figures 1b, c, PC was superior in regard to clinical activity and endoscopic appearance $\left(\mathrm{OR}=30.58,95 \%\right.$ CI: 8.01-116.82, $I^{2}=36 \%, z=5.00, p<$ $0.00001, \mathrm{OR}=36.73,95 \% \mathrm{CI}: 8.39-160.8, I^{2}=0 \%, z=4.78$, $p<0.00001$, respectively). Histological disease activity dropped under PC $\left(\mathrm{OR}=3.99,95 \% \mathrm{CI}: 1.36-11.67, I^{2}=\right.$ $33 \%, z=2.52, p=0.01$ ) (Fig. 1d) and life quality increased $\left(\mathrm{OR}=7.59,95 \%\right.$ CI: 3.33-17.31, $I^{2}=0 \%, z=4.82, p<$ $0.00001)$.

The adverse event profile of all 3 RCTs is summarized in Table 3. Most events are harmless and not related (Fig. 1e) to the study medication. None of the side effects led to discontinuation of the trial. The most frequent observation was bloating which occurred to the same extend in the verum as in the placebo group. Patients reported a relation to the study medication. Therefore, it is most likely due to the Eudragit S-100 additive, which is constituent of both preparations.

The efficacy demonstrated in the RCTs is supported by a maintenance of remission observation (Table 2) [15]. The patients who entered this study came into remission 


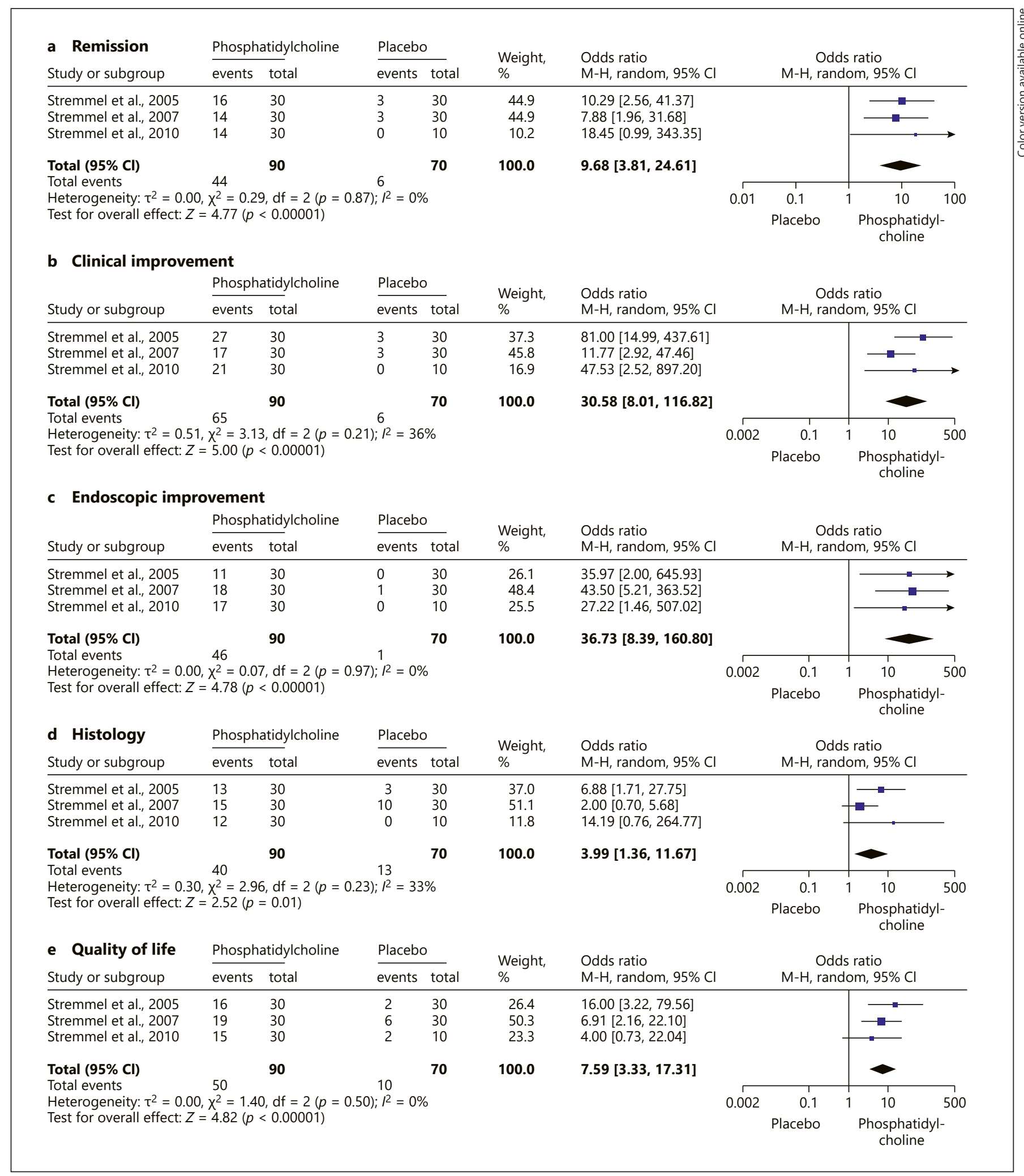

Fig. 1. Effect of $30 \%$ PC-containing lecithin on activity parameters in patients with ulcerative colitis. In the 2010 dose-finding study, the 0.5 -g daily dose was set as placebo because no clinical or endo- scopic benefit was registered. The 1-, 3-, and 4-g daily groups were considered as PC groups and combined for evaluation. PC, phosphatidylcholine; OR, odds ratio. 
Table 2. Three RCTs with delayed-release PC in patients with ulcerative colitis to achieve remission and maintenance of remission study

\begin{tabular}{|c|c|c|c|c|c|c|c|}
\hline Phase & PC, $g$ & Remission & $\begin{array}{l}\text { Clinical } \\
\text { improvement }\end{array}$ & $\begin{array}{l}\text { Endoscopic } \\
\text { improvement }\end{array}$ & $\begin{array}{l}\text { Histology } \\
\text { improvement }\end{array}$ & $\begin{array}{l}\text { Life quality } \\
\text { improvement }\end{array}$ & Cohort \\
\hline \multicolumn{8}{|c|}{ Induction of remission ( $n=160$ patients) } \\
\hline \multirow[t]{2}{*}{ IIA } & 0 & $3 / 30$ & $3 / 30$ & $11 / 30$ & $3 / 30$ & $2 / 30$ & \multirow{2}{*}{$\begin{array}{l}\text { Active UC (efficacy testing), } \\
n=60[12]\end{array}$} \\
\hline & 2 & $16 / 30$ & $27 / 30$ & $0 / 30$ & $13 / 30$ & $16 / 30$ & \\
\hline \multirow[t]{2}{*}{ IIA } & 0 & $3 / 30$ & $3 / 30$ & $1 / 30$ & $10 / 30$ & $5 / 30$ & \multirow{2}{*}{$\begin{array}{l}\text { Steroid refractory colitis } \\
\text { (efficacy testing), } n=60[13]\end{array}$} \\
\hline & 2 & $12 / 30$ & $15 / 30$ & $2 / 30$ & $15 / 30$ & $13 / 30$ & \\
\hline \multirow[t]{5}{*}{ IIB } & 0.5 & $0 / 10$ & $0 / 10$ & $0 / 0$ & $0 / 10$ & $1 / 10$ & \multirow{4}{*}{$\begin{array}{l}\text { Active UC (dose finding } \\
\text { study), } n=40[14]\end{array}$} \\
\hline & 1.0 & $3 / 10$ & $7 / 10$ & $5 / 10$ & $3 / 10$ & $4 / 10$ & \\
\hline & 3.0 & $5 / 10$ & $7 / 10$ & $6 / 10$ & $4 / 10$ & $6 / 10$ & \\
\hline & 4.0 & $6 / 10$ & $7 / 10$ & $6 / 10$ & $5 / 10$ & $6 / 10$ & \\
\hline & $\begin{array}{l}8 \text { weeks } \\
\text { follow up }\end{array}$ & $\begin{array}{l}26 \text { months } \\
\text { follow up }\end{array}$ & & & & & \\
\hline
\end{tabular}

Maintenance of remission ( $n=80$ patients) [15]

No PC 20/40 $2 / 20$

PC $\quad 30 / 40 \quad 10 / 30$

Data show number of patients responding in relation to total patients included in the respective groups. The analysis was performed with a delayed-release PC (30\% PC-containing lecithin encapsulated with Eudragit S-100 1:1). The PC amount provided daily is indicated. PC, phosphatidylcholine; UC, ulcerative colitis; RCTs, randomized controlled trials.

by a preceding therapy with delayed-release PC, either following 1 of the RCTs or by an individual healing attempt. The course of the colitis was followed over a total period of 26 months. The PC group performed better than the group without PC.

\section{Discussion}

The meta-analysis confirms that a 30\% PC-containing lecithin preparation in an intestinal release formulation improves the inflammatory activity in ulcerative colitis. This affects the clinical and endoscopic course, histology, and quality of life without adverse events. The median time to clinical improvement was 5 weeks [12-15]. The effect was clearly attributed to the addition of PC because all accompanying therapies were constant, at least 4 weeks prior to start of trials. Discontinuation of accompanying standard therapy was omitted for ethical reasons because it may have left the placebo group without any therapy. Clinical activity at entry was comparable in the placebo and PC-treated groups.

The observed improvement reflects the reestablishment of a protective mucus shield by filling up empty PC binding sites on mucin 2 [12]. The anti-inflammatory ef- fect of PC could in addition be due to saturation of the pathogenetic ecto-phospholipase activity of the microbiota [10]. Luminally provided PC is more easily accessible for these bacteria than breaking PC out of the mucus. Thus, PC-saturated bacteria are less aggressive toward mucus. It was also proposed that PC has an intrinsic antiinflammatory activity [11]. In contrast to these results, with $30 \%$ PC-containing lecithin in intestinal release formulation, the gastric acid-resistant $>94 \%$ PC-containing lecithin failed to show efficacy $[17,18]$.

Presence of intact PC in colonic lumen is a prerequisite for the proposed action. Gastric acid-resistant lecithin disintegrates at pH 5.5 already in the duodenum. In vivo, it is exposed to phospholipases of the pancreas, which hydrolyze PC to become absorbable. Thus, bioavailability for the colon fades. This may explain that the minimal effective dose for treatment of colitis is $3.2 \mathrm{~g}$ daily [16], in contrast to the intestinal release formulation with $1 \mathrm{~g}$ daily [14].

In further contrast to ileal release PC, gastric acid-resistant PC may be accessible to microbiota in the upper intestine for generation of trimethylamine as a potentially dangerous intermediate product. Upon conversion to trimethylamine- $\mathrm{N}$-oxide by the liver, it is a risk factor for coronary heart disease [26]. 
Table 3. AE profile of the 3 RCTs with delayed-release of PC in patients with active UC

\begin{tabular}{|c|c|c|c|c|c|c|}
\hline \multirow[t]{3}{*}{ Adverse event } & \multicolumn{3}{|c|}{$\mathrm{PC}(n=90)$} & \multicolumn{3}{|c|}{ Placebo $(n=70)$} \\
\hline & \multirow[t]{2}{*}{ AEs, $n$} & \multicolumn{2}{|c|}{$\begin{array}{l}\text { Causality to study } \\
\text { medication }\end{array}$} & \multirow[t]{2}{*}{ AEs, $n$} & \multicolumn{2}{|c|}{$\begin{array}{l}\text { Causality to study } \\
\text { medication }\end{array}$} \\
\hline & & not related & related & & not related & related \\
\hline Abdominal pain & 7 & 7 & & 5 & 5 & \\
\hline Allergic reactions & 1 & & 1 & & & \\
\hline Anal incontinence & 1 & 1 & & 3 & 2 & 1 \\
\hline Bloating & 40 & 8 & 32 & 29 & 5 & 24 \\
\hline Cardiac arrhythmia & 1 & 1 & & & & \\
\hline Circulatory dysfunction & & & & 1 & 1 & \\
\hline Cough & 1 & & 1 & & & \\
\hline Cramps & 1 & & 1 & & & \\
\hline Defecation pain & 2 & 2 & & 2 & 2 & \\
\hline Dermatological disorders & 14 & 9 & 5 & 22 & 12 & 10 \\
\hline Diarrhea/gastroenteritis & 4 & 3 & 1 & 8 & 7 & 1 \\
\hline Difficulties starting to urinate & & & & 1 & 1 & \\
\hline Dysphagia & 1 & 1 & & 1 & & 1 \\
\hline Edema & 5 & 4 & 1 & 2 & 2 & \\
\hline Fatigue & 7 & 6 & 1 & 6 & 6 & \\
\hline Fever & 1 & 1 & & 1 & 1 & \\
\hline Gum bleeding & & & & 1 & 1 & \\
\hline Halitosis & 1 & 1 & & 2 & 2 & \\
\hline Headache & 2 & & 2 & 1 & 1 & \\
\hline Hearing disorders & 1 & 1 & & 1 & 1 & \\
\hline Hot flashes & 3 & 1 & 2 & 2 & 1 & 1 \\
\hline Hyperhidrosis & 3 & & 3 & 4 & 2 & 2 \\
\hline Increased weight or appetite & 4 & 2 & 2 & 2 & 1 & 1 \\
\hline Loss of libido & & & & 1 & 1 & \\
\hline Loss of power & & & & 4 & 3 & 1 \\
\hline Loss of weight of appetite & 4 & 2 & 2 & 8 & 7 & 1 \\
\hline Mood changes & 3 & 3 & & & & \\
\hline Muscle pain & 2 & 1 & 1 & 2 & 2 & \\
\hline Nausea/vertigo & 6 & 5 & 1 & 3 & 1 & 2 \\
\hline Nervousness & 1 & 1 & & 2 & 2 & \\
\hline Other pain & 1 & 1 & & & & \\
\hline Palpitations & 1 & 1 & & 2 & 1 & 1 \\
\hline Paresthesia & 1 & 1 & & 2 & 1 & 1 \\
\hline Pruritus & 3 & 3 & & 3 & 3 & \\
\hline Pyrosis & & & & 1 & 1 & \\
\hline Rectal discharge & 7 & 7 & & 6 & 4 & 2 \\
\hline Sleep disorder & 2 & 1 & 1 & 4 & 4 & \\
\hline Susceptibility for infection & & & & 1 & & 1 \\
\hline Temporary indisposition & 1 & & 1 & 3 & 2 & 1 \\
\hline
\end{tabular}

The dose finding study was included and the ineffective $0.5 \mathrm{~g}$ PC group was taken as placebo, while the 1.0, 2.0, and 3.0 g PC groups were combined and evaluated as PC-treated collective. AE, adverse event; PC, phosphatidylcholine; UC, ulcerative colitis; RCTs, randomized controlled trials.

Another reason for therapy failure may be the use of a highly enriched (>94\%) PC-containing lecithin instead of the $30 \%$ PC-containing lecithin. The 30\% PC preparation may be more physiological and possibly more stable in its compo- sition with $30 \% \mathrm{PC}, 21 \% \mathrm{PE}$, and 9\% PI [12]. It may represent a more disperse formulation with better availability to the mucus. PE and PI were shown not to bind to mucin 2, thus enabling a physiologic selection in favor of PC [4]. 
It turned out that mesalazine acts as a detergent and prohibits PC access to the surface of the mucus. Since mesalazine is poorly absorbable, it stays in the lumen and generates with the delayed released PC a foam (micellar solution) with high intermolecular affinity, prohibiting to fill empty PC-binding sites on mucin 2 [27]. In the phase III induction of remission trial with $>94 \%$ PC-containing lecithin, the simultaneous intake of mesalazine was mandatory. This was a stricter criterion as in all the preceding trials. Most arguments are in favor of the 30\% PC-containing lecithin in intestinal release formulation. The advantage of $a>94 \%$ PC-containing lecithin is the lower amount to be taken daily and, thus, the lower amount of retarding additive. On the other hand, different physicochemical characteristics (e.g., melting point) and possible contamination with hazardous chemicals due to the enrichment process also may have to be considered.

The 30\% PC-containing lecithin was effective in regard to all of the examined activity parameters evaluated in this meta-analysis including 3 RCTs [12-15]. It was successful in active ulcerative colitis, even in steroid refractory courses, where the withdrawal of steroids was successful in $80 \%$ of the patients [13]. Apart from the meta-analysis, data of the maintenance of remission observation were added to support the view of PC efficacy [15]. The purpose of this meta-analysis targeted the awareness of treating physicians toward the efficacy of intestinal release PC, even if not applied as a therapeutic agent but just a supplementary dietary additive.

As a shortcoming of the presented concept, the fact is stressed that all studies came from 1 trial center, which makes the analysis prone to bias. The advantage is a homogenous trail arrangement. Nevertheless, the study populations were small and included heterogeneous patients with different severity of colitis or even steroid-dependent courses, which are tapering oral steroids and those treated with different doses of PC. Despite this diversity, a significant clinical improvement was registered by PC treatment throughout the total cohort.

One may argue that the meta-analysis with small trial sizes tends to show more beneficial treatment effects [28]. Although this has to be considered, the significance shown in this meta-analysis has such a large margin toward placebo that efficacy is most likely. However, for the future, it is recommended to evaluate the therapeutic efficacy in larger, multicenter trials. Intestinal-release PC may even be evaluated in patients with other chronic inflammatory bowel disorders.

The PC formulation should have chances to be provided and even to be recommended to patients with ul- cerative colitis. The pathophysiologic concept for the development of ulcerative colitis is challenging and the proposed topical PC supplementation is without apparent harm to the patients. Indeed, improvement of the disease was registered in regard to clinical, endoscopic, histologic, and life quality improvement with a 30\% PC-containing lecithin in intestinal release formulation.

\section{Statement of Ethics}

This research complies with the guidelines for human studies and includes evidence that the research was conducted ethically in accordance with the World Medical Association Declaration of Helsinki. The data were compiled from 3 previously published RCTs [12-14]. Therefore, the paper is exempt from further Ethical Committee approval. The former trials were conducted ethically in accordance with the World Medical Association Declaration of Helsinki. In this meta-analysis, data were analyzed from previous clinical trials in which informed consent had been obtained by the trial investigators.

\section{Conflict of Interest Statement}

W.S. is author of the 3 randomized controlled trials analyzed in this meta-analysis. The other authors declare no conflict of interest.

\section{Funding Sources}

This research received no external funding.

\section{Author Contributions}

Conceptualization: W.S.; validation: W.S., H.V., O.E., and R.W.; writing - original draft preparation: W.S. and R.W.; writing - review and editing: W.S., H.V., O.E., and R.W.; software: H.V. and O.E.

\section{References}

1 Johansson ME, Hansson GC. Immunological aspects of intestinal mucus and mucins. Nat Rev Immunol. 2016;16(10):639-49.

2 Butler BD, Lichtenberger LM, Hills BA. Distribution of surfactants in the canine gastrointestinal tract and their ability to lubricate. Am J Physiol. 1983;244(6):G645-51.

3 Lichtenberger LM. The hydrophobic barrier properties of gastrointestinal mucus. Annu Rev Physiol. 1995;57:565-83.

4 Stremmel W, Staffer S, Gan-Schreier H Wannhoff A, Bach M, Gauss A. Phosphatidylcholine passes through lateral tight junctions for paracellular transport to the apical side of the polarized intestinal tumor cell-line CaCo2. Biochim Biophys Acta. 2016;1861(9 Pt A):1161-9. 
5 Stremmel W, Staffer S, Schneider MJ, GanSchreier H, Wannhoff A, Stuhrmann N, et al. Genetic mouse models with intestinal-specific tight junction deletion resemble an ulcerative colitis phenotype. J Crohns Colitis. 2017; 11(10):1247-57.

6 Stremmel W, Staffer S, Weiskirchen R. Phosphatidylcholine passes by paracellular transport to the apical side of the polarized biliary tumor cell line Mz-ChA-1. Int J Mol Sci. 2019; 20(16):4034.

7 Stremmel W, Lukasova M, Weiskirchen R. The neglected biliary mucus and its phosphatidylcholine content: a putative player in pathogenesis of primary cholangitis: a narrative review article. Ann Transl Med. Forthcoming. 2021. http://dx.doi.org/10.21037/ atm-20-3591.

8 Ehehalt R, Wagenblast J, Erben G, Lehmann WD, Hinz U, Merle U, et al. Phosphatidylcholine and lysophosphatidylcholine in intestinal mucus of ulcerative colitis patients. A quantitative approach by nanoElectrospray-tandem mass spectrometry. Scand J Gastroenterol. 2004;39(8):737-42.

9 Braun A, Treede I, Gotthardt D, Tietje A, Zahn A, Ruhwald R, et al. Alterations of phospholipid concentration and species composition of the intestinal mucus barrier in ulcerative colitis: a clue to pathogenesis. Inflamm Bowel Dis. 2009;15(11):1705-20.

10 Stremmel W, Staffer S, Stuhrmann N, GanSchreier H, Gauss A, Burger N, et al. Phospholipase A2 of microbiota as pathogenetic determinant to induce inflammatory states in ulcerative colitis: therapeutic implications of phospholipase A2 inhibitors. Inflamm Intest Dis. 2018;2(3):180-7.

11 Anes E, Kühnel MP, Bos E, Moniz-Pereira J, Habermann A, Griffiths G. Selected lipids activate phagosome actin assembly and maturation resulting in killing of pathogenic mycobacteria. Nat Cell Biol. 2003;5(9):793-802.

12 Stremmel W, Merle U, Zahn A, Autschbach F, Hinz U, Ehehalt R. Retarded release phosphatidylcholine benefits patients with chronic active ulcerative colitis. Gut. 2005;54(7): 966-71.
13 Stremmel W, Ehehalt R, Autschbach F, Karner M. Phosphatidylcholine for steroid-refractory chronic ulcerative colitis: a randomized trial. Ann Intern Med. 2007;147(9):603-10.

14 Stremmel W, Braun A, Hanemann A, Ehehalt R, Autschbach F, Karner M. Delayed release phosphatidylcholine in chronic-active ulcerative colitis: a randomized, double-blinded, dose finding study. J Clin Gastroenterol. 2010; 44(5):e101-7.

15 Stremmel W, Hanemann A, Ehehalt R, Karner M, Braun A. Phosphatidylcholine (lecithin) and the mucus layer: evidence of therapeutic efficacy in ulcerative colitis? Dig Dis. 2010; 28(3):490-6.

16 Karner M, Kocjan A, Stein J, Schreiber S, von Boyen G, Uebel P, et al. First multicenter study of modified release phosphatidylcholine "LT-02" in ulcerative colitis: a randomized, placebo-controlled trial in mesalazinerefractory courses. Am J Gastroenterol. 2014; 109(7):1041-51.

17 Dignass A, Reinisch W, Horynski M, Poyda O, Armerding P, Langhorst J, et al. Efficacy and safety of gastro-resistant phosphatidylcholine (LT-02) for induction of remission in patients with mild-to-moderate ulcerative colitis refractory to mesalazine: a randomized, double-blind, placebo-controlled study (PCG-2). United Europ Gastroenterology J. 2018;6(8S):A76.

18 Dignass A, Stremmel W, Bilianskyi L, Horynski M, Fellermann K, Uebel P, et al. Efficacy and safety of gastro-resistant phosphatidylcholine (LT-02) for maintenance of remission in patients with ulcerative colitis initially refractory to mesalazine: a randomised, doubleblind, double-dummy placebo-controlled study (PCG-4). United Europ Gastroenterology J. 2018;6(8S).

19 D’Haens G, Sandborn WJ, Feagan BG, Geboes $\mathrm{K}$, Hanauer SB, Irvine EJ, et al. A review of activity indices and efficacy end points for clinical trials of medical therapy in adults with ulcerative colitis. Gastroenterology. 2007; 132(2):763-86.
20 Vecchi M, Meucci G, Gionchetti P, Beltrami M, Di Maurizio P, Beretta L, et al. Oral versus combination mesalazine therapy in active ulcerative colitis: a double-blind, double-dummy, randomized multicentre study. Aliment Pharmacol Ther. 2001;15(2):251-6.

21 Kruis W, Schreiber S, Theuer D, Brandes JW, Schütz E, Howaldt $S$, et al. Low dose balsalazide ( $1.5 \mathrm{~g}$ twice daily) and mesalazine $(0.5 \mathrm{~g}$ three times daily) maintained remission of ulcerative colitis but high dose balsalazide (3.0 g twice daily) was superior in preventing relapses. Gut. 2001;49(6):783-9.

22 Rachmilewitz D. Coated mesalazine (5-aminosalicylic acid) versus sulphasalazine in the treatment of active ulcerative colitis: a randomised trial. BMJ. 1989;298(6666):82-6.

23 Truelove SC, Richards WC. Biopsy studies in ulcerative colitis. Br Med J. 1956;1(4979): 1315-8.

24 Guyatt G, Mitchell A, Irvine EJ, Singer J, Williams N, Goodacre R, et al. A new measure of health status for clinical trials in inflammatory bowel disease. Gastroenterology. 1989; 96(3):804-10.

25 Häuser W, Dietz N, Grandt D, Steder-Neukamm U, Janke KH, Stein U, et al. Validation of the inflammatory bowel disease questionnaire IBDQ-D, German version, for patients with ileal pouch anal anastomosis for ulcerative colitis. Z Gastroenterol. 2004;42(2):1319.

26 Stremmel W, Schmidt KV, Schuhmann V, Kratzer F, Garbade SF, Langhans CD, et al. Blood trimethylamine- $\mathrm{N}$-oxide originates from microbiota mediated breakdown of phosphatidylcholine and absorption from small intestine. PLoS One. 2017;12(1): e0170742.

27 Stremmel W, Staffer S, Gehrke S. The detergent effect of mesalazine interferes with phosphatidylcholine binding to mucin 2. Inflamm Intest Dis. 2019;3(3):107-15.

28 Nüesch E, Trelle S, Reichenbach S, Rutjes AW, Tschannen B, Altman DG, et al. Small study effects in meta-analyses of osteoarthritis trials: meta-epidemiological study. BMJ. 2010;341:c3515. 